\title{
O ESPAÇO PEDAGÓGICO DAS INTERAÇÕES CULTURAIS E HUMANÍSTICAS COMO UM ESPAÇO POTENCIALMENTE EXTENSIONISTA EM CURSOS DE LICENCIATURA
}

\author{
Marcos Aurelio Zanlorenri $i^{1}$ \\ Neusa Maria Tauscheck ${ }^{2}$
}

\begin{abstract}
Resumo
Com este trabalho temos como principal objetivo apresentar o espaço pedagógico denominado: "Interações Culturais e Humanísticas" (ICH) - contido no Projeto Político Pedagógico (PPP) da Universidade Federal do Paraná (UFPR Litoral) - como um potencial espaço extensionista em cursos de licenciatura. Para tanto, nosso olhar estará voltado especificamente para o curso de Licenciatura em Geografia da UFPR Litoral, e os diálogos que esse curso propõe estabelecer com as ICH. A escolha por essa Licenciatura se deve não apenas por ser o mais recente curso da UFPR Litoral, mas, especialmente, pela diferencialidade do seu Projeto Pedagógico Curricular (PPC). Contudo, além de tratarmos do curso de Licenciatura em Geografia, também, apresentaremos duas experiências que caracterizam as ICH como um espaço potencialmente extensionista. As Interações Culturais e Humanísticas têm como objetivo promover a interação vertical (educandos de turmas em fases diferentes dos cursos) e horizontal (educandos de cursos diferentes no mesmo espaço). Trata-se de um espaço pedagógico que, alicerçado nos princípios da Educação Popular, tem como ênfase a construção coletiva e autogestionária dos processos; a fim de proporcionar percepções e trocas de saberes e experiências; o que o torna um espaço de reflexão e ação. Sendo assim, esse espaço pedagógico se caracteriza como fundamental para os cursos de formação de docentes, pois, pode possibilitar formas de compreensão e vivências acerca da espacialidade e do território, na medida em que se constitui como articulador de diálogos os cursos de licenciatura e os modos de vida locais.
\end{abstract}

Palavras-Chave: Educação Popular. Extensão universitária. Formação de professores. Interações Culturais e Humanísticas.

\section{Introdução}

Neste texto apresentamos reflexões sobre a possibilidade de diálogo entre a formação de professores de geografia e o espaço pedagógico "Interações Culturais e Humanísticas" (ICH), entendendo este como um espaço potencialmente extensionista. Trata-se de um espaço pedagógico que visa a problematização das hierarquias existentes entre os diferentes saberes e culturas, e o fortalecimento de compromissos éticos e políticos para além daqueles

\footnotetext{
${ }^{1}$ Professor associado da Universidade Federal do Paraná - UFPR Litoral, coordenador do curso de Licenciatura em Geografia da UFPR Litoral, coordenador do projeto de extensão "Diálogos de Saberes no Litoral Paranaense: construindo interfaces entre a comunidade e a escola" e membro do Grupo Interdisciplinar de Estudos e Pesquisas para o Desenvolvimento Sustentável do Litoral do Paraná. Email:marcos.zan@terra.com.br

${ }^{2}$ Professora assistente da Universidade Federal do Paraná - UFPR Litoral, vice coordenadora do projeto de extensão "Diálogos de Saberes no Litoral Paranaense: construindo interfaces entre a comunidade e a escola", doutoranda no Programa de Pós-Graduação em Educação (PPGE) da UFPR e membro do Núcleo de Pesquisas em Publicações Didáticas da UFPR. E-mail: neusat45@gmail.com
} 
valorizados na lógica do mercado. Essa possibilidade de diálogo vem ao encontro do que diz Meneses ao afirmar que "a entrada no século 21 assinala, de forma permanente, a necessidade de uma mudança nos projetos epistêmicos, seja qual for a sua origem”. (MENESES, 2014, p. 91).

Essa necessidade se mostra ainda mais premente, na medida em que as propostas pedagógicas voltadas à formação de professores, oriundas de uma visão iluminista de conhecimento, comumente reafirmam uma hierarquia entre saberes. Uma visão que, direta ou indiretamente, contribui para a produção de sociedades que se definem como superiores a outras, impondo uma visão monocultural, ou seja, "esse posicionamento teórico e metodológico é a afirmação de uma única ontologia, de uma epistemologia, de uma ética, de um pensamento único, e sua imposição como universal”. (MENESES, 2014, p. 93)

Assim, para apresentarmos o processo de construção desse diálogo, que pode aproximar os debates entre a formação do licenciado em geografia, a extensão universitária, e outras formas de ver a Educação, destacamos: o contexto de construção do curso de Licenciatura em Geografia; o diálogo entre a ICH, a Educação Popular e a descolonização dos saberes; logo em seguida, duas narrativas sobre vivências de ICH que podem ser caracterizadas como extensionistas, às quais denominamos de Cenário 01 e Cenário 02e, por fim; procuramos tecer comentários sobre como pensamos a relação dialógica entre a proposta educativa da ICH e a Licenciatura em Geografia como estratégias pedagógicas e políticas na perspectiva da Educação Popular, em especial como um espaço potencialmente extensionista.

\section{Contexto de construção do curso de Licenciatura em Geografia}

A partir de 2003 o Ministério da Educação (MEC) iniciou o processo de desenvolvimento e implementação de uma série de políticas públicas voltadas a todos os níveis da educação brasileira, por meio de um macro programa educacional, que tinha a finalidade de dar cumprimento à Lei de Diretrizes e Bases da Educação Nacional - LDB (Lei 9394/96) e atender aos objetivos e metas do Plano Nacional de Educação (PNE). Dentre os diversos subprogramas ligados a esse programa maior, destacamos aqueles relativos à expansão da Educação Superior Pública, em especial o Programa EXPANDIR (Programa de Expansão da Educação Superior Pública SESu/MEC), que teve seu desenvolvimento no 
período de 2003 a $2006^{3}$, e o Programa REUNI (Programa de Apoio a Planos de Expansão e Reestruturação de Universidades Federais), que teve sua implementação entre 2007 e 2012.

Foi nesse contexto que, em 2005, se deu a criação do Setor Litoral da Universidade Federal do Paraná - UFPR. Instalada em um território "esquecido" pelo poder público, o que reflete diretamente nos modos de vida das populações que ali coabitam - predominantemente populações tradicionais constituídas por caiçaras ${ }^{4}$, ribeirinhos, pescadores artesanais, populações de manguezais, quilombolas, entre outros - por meio de uma concepção de educação anti-hierárquica e antiexclusivista “[...] toma como princípio a reflexão acerca da realidade concreta do lugar, como fonte primeira, para, em diálogo com o conhecimento sistematizado, tecer a organização curricular e o desenvolvimento de projetos que devem partir dos alunos e envolver as/os educadoras/es e a comunidade.” (UFPR LITORAL, 2008, p. 06)

Dessa forma, por meio de uma proposta pedagógica pautada no trabalho por projetos que, através de uma ação interdisciplinar e extensionista tem como principal virtude a articulação entre o conjunto de ações e atividades formativas da universidade, com a realidade das comunidades locais - o Projeto Político Pedagógico da UFPR Litoral (PPP) subsidia uma formação humana, profissional, política e científica com/para essas populações, a fim de que elas se empoderem e que possam, de forma protagonista e autônoma, enfrentar a complexa e contraditória sociedade globalizada na quais se encontram imersas.

É nesse contexto que se insere o curso de Licenciatura em Geografia, como consequência do encerramento dos cursos de Tecnologia em Orientação Comunitária e Bacharelado em Informática e Cidadania na UFPR Litoral. A partir de 2014 os educadores desses dois cursos passaram a se reunirem com a finalidade de pensar um novo projeto de curso que possibilitasse dar vazão ao acúmulo de suas experiências de ensino, extensão e pesquisa, ao mesmo tempo em que, oportunizasse a criação de outras maneiras de fazer educação, de forma a atender as históricas demandas dos sete municípios litorâneos.

Na medida em que se insere no PPP da UFPR Litoral, o Curso de Licenciatura em Geografia busca materializar sua proposta, também, a partir da articulação de três grandes fases:

\footnotetext{
${ }^{3}$ Cabe destacar que algumas ações do Programa EXPANDIR estenderam-se até 2010, deste modo ações deste programa foram realizadas concomitantemente às ações do REUNI.

${ }^{4}$ Entende-se por caiçaras as comunidades formadas pela mescla da contribuição étnico-cultural dos indígenas, dos colonizadores portugueses e, em menor grau, dos escravos africanos. Os caiçaras apresentam uma forma de vida baseada em atividades de agricultura itinerante, da pequena pesca, do extrativismo vegetal e do artesanato. Essa cultura desenvolveu-se principalmente nas áreas costeiras dos atuais estados do Rio de Janeiro, São Paulo, Paraná e norte de Santa Catarina. (Diegues, 2004, p. 9) 
1- conhecer e compreender; 2- compreender e propor e, 3- propor e agir. Essas fases temporais são desenvolvidas dentro de três grandes módulos que dialeticamente se constituem e organizam todos os cursos. O primeiro módulo é constituído por Projetos de Aprendizagem, o segundo formado pelas Interações Culturais e Humanísticas e o terceiro módulo organizado pelos Fundamentos Teórico-práticos. (UFPR LITORAL, 2008, p. 07).

Nesse texto, contudo, vamos nos ater apenas ao segundo módulo ${ }^{5}$, denominado "Interações Culturais e Humanísticas". Vejamos, portanto, de que forma o curso de Licenciatura em Geografia, por meio do seu PPC, pretende viabilizar a formação de professores de geografia na perspectiva da Educação Popular - um dos fundamentos do curso, juntamente com o paradigma decolonial e o Buen Vivir - tendo como elemento articulador o espaço pedagógico das Interações Culturais e Humanísticas e como este pode se constituir em um espaço potencialmente extensionista.

\section{Olhares para a proposta do espaço pedagógico ICH - Interações Culturais Humanísticas}

No Projeto Político Pedagógico da UFPR Litoral e, consequentemente, no Projeto Pedagógico Curricular do curso de Licenciatura em Geografia, a proposta educativa presente nas diretrizes da ICH destaca-se como um componente curricular diferencial na prática pedagógica da UFPR Litoral. As ICH trazem como um de seus princípios o rompimento da tradição de oferta de disciplinas e módulos, afinal, este espaço pedagógico pode ser proposto por educandos, servidores (da administração e/ou docentes) e comunidade, desde que mediado por um servidor docente e efetivamente construído (os objetivos, encaminhamentos metodológicos, temas a serem abordados e processos avaliativos) coletivamente, articulando desejos individuais na construção de atividades coletivas.

De modo geral, as ICH se caracterizam como espaços pedagógicos, juntamente com os Fundamentos Teórico-Práticos e os Projetos de Aprendizagem. Entretanto, destaca-se por ter como principal objetivo a promoção da interação vertical (turmas em fases diferentes dos

\footnotetext{
${ }^{5}$ Neste texto o uso da expressão "Interação Cultural Humanística- ICH" está associado a termos como: "módulo" [PPP - Setor Litoral], "eixo pedagógico" [PPC - Licenciatura em Geografia]. Contudo nós optamos em associar a ICH à expressão "espaço pedagógico", por acreditarmos que a proposta da ICH não se fecha nela mesmo. Como constructo curricular a expressão "espaço" associada ao caráter pedagógico possibilita que o licenciado experiencie a construção dos conhecimentos de forma dinâmica e transformadora. O uso da expressão "espaço pedagógico", portanto, busca dar a dimensão de uma construção formativa dentro de contextos que não se limitem a algo pontual e estático. 
cursos) e horizontal (cursos diferentes no mesmo espaço) com ênfase nas construções coletivas, percepções e trocas de experiências, em um espaço de ação e reflexão que não se limita aos muros da universidade. Nesse sentido, essas interações devem ser construídas simétrica e dialogicamente entre educandos, comunidades e servidores (da administração e/ou docentes). Não apenas reconhecendo e valorizando os diferentes saberes e lugares culturais que compõem a vida social, mas problematizando e questionando as hierarquias existentes entre esses diferentes saberes e culturas, a fim de fortalecer por meio de relações autogestionárias, compromissos éticos e políticos para além daqueles valorizados na lógica do mercado.

Por seu caráter autogestionário, além de descentralizar e decolonizar saberes, as ICH se constituem como um espaço pedagógico que está em permanente construção na esfera da sua logística educativa, e seus encaminhamentos são os mais distintos/diversos/plurais, assim como deve ser o universo acadêmico. Nesse sentido, importa que essa construção constante, além de potencializar a capacidade de elaboração de objetivos factíveis de serem atingidos e coerentes com o Projeto Político Pedagógico, também não se limite à definição das clássicas disciplinas optativas ofertadas dentro dos cursos existentes na UFPR Litoral. Essa redução da proposta da ICH poderia resultar na fragmentação e verticalização hierárquica de oferta dos espaços educativos, esvaziando suas dimensões pedagógicas de caráter libertário que estimulam uma atitude coletivo-solidária dos processos de leitura do mundo.

Esses pressupostos gerais apresentam direções sobre as formas de pensar a organização desse espaço pedagógico, sua construção e processos avaliativos. Dentro dessa lógica educativa, trazemos neste contexto possíveis relações entre o espaço pedagógico das ICH, o debate da Educação Popular e os princípios do paradigma decolonial.

\section{Diálogo entre a ICH, a Educação Popular e a decolonização dos saberes: percursos e novos olhares para formação na Universidade.}

Se observarmos os princípios das Interações Culturais e Humanísticas (simetria e dialogicidade entre estudantes, comunidades e servidores - da administração e/ou docentes; reconhecimento e valorização dos diferentes saberes e lugares culturais que compõem a vida social; problematização/questionamento das hierarquias existentes entre esses diferentes saberes e culturas; fortalecimento de compromissos éticos e políticos para além daqueles valorizados na lógica do mercado; vivência e adensamento de relações autogestionárias) 
vamos perceber que eles possuem estreitas relações tanto com a perspectiva da Educação Popular, como com o paradigma decolonial e com a extensão universitária.

Apenas no sentido de melhor explicitarmos essas relações, entendemos ser necessário abordar, ainda que de forma breve, esses dois fundamentos (a perspectiva da Educação Popular e o paradigma decolonial), por conta da importância que foi atribuída a eles no Projeto Pedagógico do curso de Licenciatura em Geografia. Comecemos pela perspectiva da Educação Popular.

Referencial frequente nos discursos de distintos grupos populares como, por exemplo, nos movimentos sociais, entendemos que nesse contexto é importante destacarmos o papel da Educação Popular, também no Ensino Superior, e a partir de duas dimensões que lhe são características: 1. A dimensão política e,2. A dimensão pedagógica. Nesse sentido, primeiramente é importante que se diga que: pensar o Ensino Superior desde a perspectiva da Educação Popular é colocar em questão as relações entre a universidade e a sociedade. Universidade essa que, é preciso reconhecer, desde sempre primou por uma organização disciplinar do conhecimento, comumente atrelada às demandas de uma sociedade com base elitista, conservadora e excludente.

É exatamente nessa lacuna que a perspectiva da Educação Popular se apresenta como potencial de atuação nas dimensões políticas e pedagógicas. No que se refere à dimensão política é necessário perceber que ela se dá no terreno do saber e no terreno do poder, tanto no âmbito macro (no qual questiona e busca transformar as relações de dominação na institucionalidade, e nas políticas públicas nas diferentes esferas estatais), como no âmbito micro (no qual, não apenas questiona o poder dominante no interior das instituições educativas, mas também produz alternativas para a transformação dessas relações de poder, nas práticas pedagógicas do cotidiano). De qualquer forma, entendemos que "[...] é importante que a partir da educação popular se retome com mais força a discussão sobre o âmbito político e o que isso significa numa perspectiva emancipadora”. (CARRILLO, 2013, p. 25).

No que se refere à dimensão pedagógica é comum encontrarmos uma crítica à Educação Popular na qual se afirma que o caráter político comumente se sobrepõe ao caráter pedagógico. Nesse sentido, entendemos que "[...] a educação popular é uma entre as muitas presentes em nossos países e se diferencia por sua intencionalidade emancipadora e sua opção pelo campo popular”. (CARRILLO, 2013, p. 26). Ou seja, não há como desvincular o caráter pedagógico do caráter político das práticas de Educação Popular, na medida em que: 
[...] em todo campo social coexistem saberes socialmente legitimados junto com outros subjugados, mas que, como os outros saberes, também circulam por múltiplos âmbitos e de diversas formas; isto se expressa em uma tensão permanente acerca de quem pode falar "verdadeiramente" sobre um determinado assunto, como a saúde ou a política, por exemplo, e acerca de qual assunto é mais ou menos importante, por exemplo, o político ou o pedagógico. (CARRILLO, 2013, p. 27).

Por isso consideramos que, apesar dessa crítica, o mais importante é o grande número de valiosas experiências educacionais, como as $\mathrm{ICH}$, por exemplo, as quais devem ser sistematizadas e compartilhadas. Agora abordaremos o paradigma decolonial.

Da mesma forma como fizemos com a perspectiva da Educação Popular, vamos nos ater à relação entre a universidade e o paradigma decolonial. Nesse sentido, pensar essa relação significa pensar a questão da colonialidade do saber, na medida em que:

[...] laformaciónprofesional [que ofrecelauniversidad], lainvestigación, los textos que circulan, las revistas que se reciben, los lugares donde se realizanlosposgrados, los regímenes de evaluación y reconocimiento de supersonal académico, todo apuntahaciala sistemática reproducción de una mirada del mundodesde las perspectivas hegemónicas del Norte $^{6}$. (LANDER ${ }^{7}$ citado por CASTRO-GÓMEZ, 2007, p. 79).

A partir dessa constatação, as perguntas que se colocam são: como e o que significa decolonizar a universidade? Para tentar responder a essas questões é preciso o entendimento de que a construção de um projeto decolonial de universidade passa, necessariamente, pela negação da afirmação de que a universidade é o único lugar de produção de conhecimento. Negação essa que terá como consequência direta a construção de práticas transdisciplinares e transculturais ${ }^{8}$, resultando em um profundo diálogo de saberes.

Ao nos referirmos a um profundo diálogo de saberes queremos evidenciar que se trata de uma radical transformação estrutural e sócio-históricados espaços educativos e não

\footnotetext{
${ }^{6}[\ldots]$ a formação profissional [oferecida pela universidade], a pesquisa, os textos que circulam, as revistas recebidas, os lugares onde os programas de pós-graduação se realizam, os sistemas de avaliação e reconhecimento do pessoal académico, tudo aponta para a reprodução sistemática de um olhar para o mundo desde as perspectivas hegemônicas do Norte. (Tradução nossa).

${ }^{7}$ LANDER, E. ¿Conocimiento para qué? ¿Conocimiento para quién? Reflexiones sobre la universidad y la geopolítica de los saberes hegemónicos. In: CASTRO-GÓMEZ, S. (Comp.). La reestructuración de las ciências sociales en América Latina. Bogotá: Centro Editorial Javeriano, Instituto Pensar, Pontificia Universidad Javeriana, 2000.

${ }^{8}$ Os termos "transdisciplinaridade" e "transculturalide" remetem aqui à perspectiva de Santiago Castro-Gomes apontada em CASTRO-GÓMES, S. Decolonizar la universidad: la hybris del punto cero y el diálogo de saberes In: CASTRO-GÓMES, S.; GROSFOGUEL, R. (Ed.). El giro decolonial: reflexiones para una diversidad epistémica más allá del capitalismo global. Bogotá: Siglo del Hombre Editores; Universidad Central; Instituto de Estudios Sociales Contemporáneos; Pontificia Universidad Javeriana; Instituto Pensar, 2007. p. 79-91.
} 
meramente o "[...] encontro do Ocidente com o Outro, mas um giro epistêmico capaz de estimular novos conhecimentos e outras interpretações de mundo, sem perder de vista os condicionantes da colonialidade". (MASO e YATIM, 2014, p. 47).

Assim, no sentido de responder às lógicas das colonialidades do poder, do ser e do saber, evidencia-se não apenas a necessidade, mas a urgência em desenvolver outras experiências políticas, vivências culturais, alternativas econômicas e produções de conhecimento que valorizem a interação entre teoria e prática, a fim de buscar o diálogo com as lutas sociais, populares e subalternizadas dos povos que compuseram e compõem a América Latina.

Trata-se de um fazer pedagógico que precisa combater o analfabetismo biográfico (local e comunitário), lendo a vida das gentes e dos povos, suas tradições, suas lutas, saberes, históricos e contextuais, exige uma epistemologia no plural, que se pergunta: O que sabemos?, O que importa conhecer? $O$ que é prioridade na afirmação de quem somos e do que buscamos ser? Exercício ético e político de democratização do saber como pertencente ao comunitário [...].(Peters, Schonrr e Tauscheck, 2013, p. 246).

É nesse sentido que as ICH e suas práticas se apresentam como potência para o processo de decolonização dos saberes, para ações extensionistas e, consequentemente, para o processo de construção de um projeto decolonial e popular de universidade, a partir da perspectiva de imbricar, transformar suas aproximações com a sociedade por meio da relação dialógica proposta por Paulo Freire em sua obra. Vejamos, na sequência, alguns exemplos dessas práticas a partir do relato de duas experiências de $\mathrm{ICH}$, Cenário 01: ICH "Feito à mão" e, Cenário 02: ICH “Cultura das Populações Tradicionais do Litoral do Paraná”.

\section{Cenário 01: ICH "Feito à mão".}

Vivenciar a ICH é um desafio educativo que começa com a escolha da temática. A ICH "Feito à mão" teve seu início nas dependências do Setor Litoral e tinha como característica propor aos educandos e comunidade local oficinas de práticas de confecção de artesanato como, por exemplo, feitura de bonecas de pano. Entretanto, em 2011, com a ocorrência de um grande volume de chuvas houve uma série de deslizamentos de terra nas cidades litorâneas de Morretes e Antonina. Cidades localizadas a 50 e 70 quilômetros de Matinhos, nas quais uma parcela da população foi diretamente atingida, sendo necessária a transferência de famílias das áreas de maiores riscos. Nesse contexto, a UFPR Litoral 
organizou eventos $^{9}$ na universidade, bem como atividades nas comunidades. Assim, a ICH "Feito à mão" ultrapassou os muros da universidade e passou a ocorrer na Comunidade do Bairro Central, na cidade de Morretes, como uma forma de aproximar os educandos de uma comunidade do campo e construir um espaço de trocas de saberes e com a intenção de empoderamento econômico das mulheres, por meio da produção e comercialização dos produtos artesanais. O objetivo era compreender como a valorização do artesanato passa pelo conhecimento da cultura e de elementos da natureza, que estão agregados aos objetos a serem comercializados.

Nesse aspecto, educandos do curso de Licenciatura em Artes contribuíram com o diálogo - por meio de rodas de conversas - sobre o olhar estético do artesão, a escolha de cores e junção de técnicas diversas ao um objeto artesanal, como o uso da fibra do cipó Imbée da bananeira ${ }^{10}$. Nessa perspectiva da troca de saberes, houve momentos da participação de uma artesã da comunidade que é referência na confecção de produtos artesanais da fibra do cipó e da bananeira. Importante destacar aqui o papel das rodas de conversas nesse processo. Prática comum na perspectiva da Educação Popular, as:

[...] rodas de conversas possibilitam encontros dialógicos, criando possibilidades de produção e ressignificação de sentido - saberes - sobre as experiências dos partícipes. Sua escolha se baseia na horizontalização das relações de poder. Os sujeitos que as compõem se implicam, dialeticamente, como atores históricos e sociais críticos e reflexivos diante da realidade. Dissolve-se a figura do mestre ${ }^{11}$, como centro do processo, e emerge a fala como signo de valores, normas, cultura, práticas e discurso. (SAMPAIO et al. 2014, p. 1301).

A construção do diálogo entre as pessoas da comunidade de Sítio Grande, em Morretes, e os educandos da UFPRLitoral, possibilitou acesso a vivências ressignificadas na formação dos educandos a partir da materialidade dos sujeitos. Os educandos não chegaram com propostas prontas e acabadas para a comunidade. Foi por meio das rodas de conversas que os encaminhamentos das atividades das $\mathrm{ICH}$ foram sendo definidos e redesenhados. Desde as técnicas do artesanato que seriam socializadas, as atividades com as crianças, os

\footnotetext{
${ }^{9}$ Fórum das Comunidades do Litoral do Paraná - FOCO (I e II) nos anos de 2011 e 2012 com a participação de vários segmentos da sociedade. Lideranças e comunidades envolvidas, representantes de órgãos estatais, educadores e educandos da UFPR.

${ }^{10} \mathrm{O}$ uso do cipó é uma prática artesanal muito conhecida nas regiões litorâneas brasileiras. Para saber mais: VIEIRA, P. M.; TREVISAN, A. C. D.; FANTINI, A. C. A extração de raízes aéreas de imbé (Philodendron corcovadense) em Garuva, Santa Catarina. Rev. Bras. de Agroecologia. 9(2): p. 173-184, 2014. Disponível em:<http://orgprints.org/27423/1/Vieira_A\%20extra\%C3\%A7\%C3\%A3o\%20de\%20raizes\%20a\%C3\%A9reas $\% 20 \mathrm{de} \% 20 \mathrm{imb} \% \mathrm{C} 3 \% \mathrm{~A} 9 . \mathrm{pdf}>$

${ }^{11}$ Freire P. Pedagogia do Oprimido. $17^{\mathrm{a}}$ ed. Rio de Janeiro: Paz e Terra; 1970. 
desafios de sua comercialização, a identidade dos sujeitos com a comunidade e sua cultura, até a confecção do lanche da tarde, foram realizados coletivamente, procurando valorizar os produtos da região como forma identitária da cultura local. Houve a preocupação constante de estabelecer diálogos diretos entre os educandos, educadores e a comunidade, como forma de estabelecer vínculos éticos. Como nos fala Freire:

Ser dialógico, para o humanismo verdadeiro, não é dizer-se descomprometidamente dialógico; é vivenciar o diálogo. Ser dialógico é não invadir, é não manipular, é não sloganizar. Ser dialógico é empenhar-se na transformação constante da realidade. Esta é a razão pela qual, sendo o diálogo o conteúdo da forma de ser própria à existência humana, está excluído de toda relação na qual alguns homens sejam transformados em 'seres para outro' por homens que são falsos 'seres para si'. É que o diálogo não pode travar-se numa relação antagônica. O diálogo é o encontro amoroso dos homens que, mediatizados pelo mundo, o 'pronunciam', isto é, o transformam, e, transformando-o, o humanizam para a humanização de todos (FREIRE, 1983, p. 43). [...] O que se pretende com o diálogo, em qualquer hipótese (seja em torno de um conhecimento científico e técnico, seja de um conhecimento 'experiencial'), é a problematização do próprio conhecimento em sua indiscutível reação com a realidade concreta na qual se gera e sobre a qual incide, para melhor compreendê-la, explicá-la, transformá-la. (Ibid., p. 52).

Sendo assim, no cuidado em construir uma proposta dialógica, a ICH "Feito à Mão", foi realizada durante o período de um ano e meio, e, assim, vivenciados vários momentos de aprendizagem com as crianças e mulheres que habitam o entorno do Casarão dos Malucelli Comunidade de Sítio Grande. Ocorreram oficinas de diferentes técnicas de artesanato: boneca de pano, fibra de bananeira e de cipó, crochê, pinturas, mosaico. As oficinas foram formas de conhecermos a comunidade e acima de tudo criar um contexto no qual os educandos saíssem dos muros da universidade para um espaço pedagógico que os aproximassem com o que de fato pensamos ser uma das funções da Universidade: estabelecer relações dialógicas com as comunidades, com a sociedade, de forma que as pessoas construam práticas de cuidado de si e do outro.

\section{Cenário 02: ICH “Cultura das Populações Tradicionais do Litoral do Paraná”.}

Como afirmamos anteriormente, as ICH têm como principal objetivo a promoção da interação vertical (turmas em fases diferentes dos cursos) e horizontal (cursos diferentes no mesmo espaço) com ênfase nas construções coletivas, percepções e trocas de experiências, em um espaço de ação e reflexão. Contudo, apesar de viável e desejável, esse arranjo proposto 
para as ICH tornou-se um desafio para educandos da Turma Guará ${ }^{12}$ do curso de Licenciatura em Educação do Campo da UFPR Litoral. O desafio se deve à diferencialidade metodológicoestrutural adotada pelo curso, pautada em momentos educativos de itinerância e alternância, momentos esses que foram considerados na construção da ICH.

Cabe, portanto, explicar que a alternância presente na proposta curricular da Licenciatura em Educação do Campo tem como princípio a vivência de educandos e educadores em dois tempos pedagógicos distintos: Tempo Universidade - TU e, Tempo Comunidade - TC. De forma breve estes se definem como: TU atividades dos espaços pedagógicos que ocorrem na sede da UFPR Litoral, situada no munícipio de Matinhos Paraná e, o TC, como o tempo em que os educandos do campo retornam às suas comunidades para aprofundar e relacionar os saberes do TU com e nos seus cotidianos. Nesta perspectiva o currículo passa a ser:

(...) pensado como um instrumento de luta, uma forma de contrapor-se à fragmentação do trabalho pedagógico e sua rotina, à dependência e aos efeitos negativos do poder autoritário e centralizador dos órgãos administrativos, levando-se me consideração os princípios democráticos, participativos, amplos, motivadores, criativos e eficientes. É peça chave dos processos educativos porque trata das finalidades e das metas, dá sentido e define a formação por alternância. (FONSÊCA e MEDEIROS, 2006,p.111).

Quanto à itinerância, historicamente o Movimento dos Trabalhadores Sem Terra MST possui no Brasil um vasto conjunto de experiências de práticas pedagógicas que dão identidade a esse movimento e que garantem a educação aos assentados em todo o país, sendo a itinerância uma dessas práticas.

A partir da premissa de que na formação do educador do campo é preciso sentir-se pertencente ao território que habita, foi proposto para a Turma Guará, momentos de itinerância para que os saberes da ICH fossem vivenciados, haja vista que vários educandos que habitam no continente não conheciam as ilhas em que outros educandos habitam muito menos os trajetos que estes fazem enfrentando as condições adversas do mar cada vez que frequentam o Tempo Universidade.

\footnotetext{
${ }^{12}$ Turma Guará é a terceira turma ofertada pelo Curso de Licenciatura em Educação do Campo da UFPR Litoral. Turma com 55 educandos que vivem no Território do Litoral: pescadores artesanais, agricultores familiares, educadores dos anos iniciais de escolas do campo, pequenos proprietários de comércio ligados à agricultura, quilombolas e demais jovens que possuem o perfil dos sujeitos do campo. 
Neste contexto da ICH "Cultura das Populações Tradicionais do Litoral do Paraná", realizada no ano de 2016 , teve como princípio a construção coletiva da sua ementa ${ }^{13}$ e dos encaminhamentos realizados. Os educandos do curso são moradores de comunidades ilhéus ou do continente, habitam lugares em que a atividades de cultivo, pesca ou comercialização ocorre por meio de produtos/elementos do território do Litoral, ou são educadores do/no campo. Adotando esta característica como premissa, a proposta da ICH teve como intenção central, além do aprofundamento dos conceitos de cultura tradicional do litoral paranaense, também oportunizar trabalhos de campo que foram denominados de itinerância nas comunidades, haja vista o envolvimento exigido de todos os participantes.

No processo de construção dos encaminhamentos da ICH a escolha de comunidades como as da Ilha de Superagüi, da Ilha Rasa e do Rio Sagrado, proporcionaram vivências sobre e nas culturas litorâneas. Vivências como os desafios do transporte de barco do continente para algumas ilhas que, além de moroso tem um alto custo, entretanto de belezas que poucos dos educandos que habitam no continente conheciam. A cultura do Fandango ${ }^{14}$, vivenciada por meio das rodas de conversas com moradores, a alimentação com receita própria de cada comunidade, as músicas e as danças foram momentos de trocas de saberes que traduziram a intenção da itinerância. Os debates que ocorreram no espaço da ICH em sala de aula possibilitaram a construção de novos conhecimentos para todos os envolvidos. Debates em que conceitos como "patrimônio material e imaterial", "comunidade tradicional" e o "ser caiçara", entre outros, assumem papel fundamental na formação do licenciado, na medida em que possibilitam a tomada de consciência de que além dos saberes convencionais da área do conhecimento - Ciências da Natureza - é necessário compreendera configuração espacial do Território do Litoral Paranaense, suas histórias, sua cultura, seus desafios e contradições.

Nestes dois relatos os cenários escolhidos se constituem como indicativos de como foi pensado o espaço pedagógico da ICH e sua interface com o PPC da Geografia.

\footnotetext{
${ }^{13}$ EMENTA: Pesquisas dos registros sobre as tradições culturais em nosso litoral. Patrimônio Material: cultivos, artesanato, pesca, fabricação de canoa de um pau só, gastronomia, arquitetura. Patrimônio Imaterial: lendas, histórias, simpatias, músicas, danças, ritos religiosos/espiritual, saúde, costumes do cotidiano.

${ }^{14}$ Fandango Caiçara/Descrição: O Fandango Caiçara é uma expressão musical-coreográfica-poética e festiva, cuja área de ocorrência abrange o litoral sul do estado de São Paulo e o litoral norte do estado do Paraná. Essa forma de expressão possui uma estrutura bastante complexa e se define em um conjunto de práticas que perpassam o trabalho, o divertimento, a religiosidade, a música e a dança, prestígios e rivalidades, saberes e fazeres. O Fandango Caiçara se classifica em batido e bailado ou valsado, cujas diferenças se definem pelos instrumentos utilizados, pela estrutura musical, pelos versos e toques. Nos bailes, como são conhecidos os encontros onde há Fandango, se estabelecem redes de trocas e diálogos entre gerações, intercâmbio de instrumentos, afinações, modas e passos viabilizando a manutenção da memória e da prática das diferentes músicas e danças. O Fandango Caiçara é uma forma de expressão. Fonte: http://portal.iphan.gov.br/bcrE/pages/folBemCulturalRegistradoE.jsf\%3Bjsessionid=C01369A0A0489EA779 A1559B5F8FAAEC?idBemCultural=0_\%5Bd36_\%4018c5551n\%5D8\%3Am208z\%40s1\%5 


\section{Relação dialógica entre a proposta educativa da ICH e a Licenciatura em Geografia.}

Como anteriormente afirmado, a proposta do curso possui princípios fundantes que visam à formação do licenciado em geografia, na perspectiva da compreensão do território, do bem viver ${ }^{15}$, do respeito à natureza como forma de estar no mundo, de coabitar como o outro. No PPC de Geografia, os princípios e intencionalidades contribuem para a:

(...) compreensão de que inexiste democracia sem a democratização das terras e dos territórios de vida dos sujeitos. Compreender as expressões das desigualdades sócio econômicas por meio da leitura das diversas paisagens e espaços vividos, conhecer a lógica produtora e legitimadora das desigualdades, estabelecer estratégias políticas de democratização das terras, influenciando nos conflitos por territórios e, portanto, por direitos, é papel fundamental do ensino da geografia em todos os níveis. (UFPR LITORAL, 2016, p. 04).

Ao optar por uma perspectiva emancipatória na formação do licenciado, o acesso a diferentes saberes vivenciados na ICH tecem novos e adensados olhares para o território. A $\mathrm{ICH}$, como espaço pedagógico que promove práticas simétricas aborda processos de aquisição do conhecimento que não se restringem a saberes hegemônicos de parcelas da sociedade. Ao propor a construção coletiva, as possibilidades de múltiplas vozes surgem, fazendo com que os conhecimentos sobre os territórios sejam múltiplos e politicamente datados.

A construção do espaço pedagógico da ICH no curso de Geografia, nesse sentido, é redimensionada a partir do momento em que suas temáticas possam, também, estar interligadas com o observatório das questões territoriais, na medida em que:

- Pode auxiliar a fortalecer processos de (re)conhecimento do litoral por meio de um observatório das questões territoriais que possa fornecer bases de dados e materiais cartográficos para outros cursos;

- Este observatório será instalado nas escolas públicas, pois servirá também de base territorial para o desenvolvimento de processos educativos voltados

\footnotetext{
${ }^{15}$ BIEN VIVIR, VIVIR BIEN, bem viver (SUMAK KAWSAY em quéchua equatoriano ou SUMA OAMAÑA em aimará boliviano): "A noção do SumakKawsayquer tornar a sociedade responsável pela maneira através da qual produz e reproduz suas condições de existência, a partir de uma lógica marcada pela ética, na qual as situações particulares formam o interesse geral, e o bem-estar de uma pessoa não se constrói sobre os demais, mas sim baseado no respeito aos outros, isto é, meu bem-estar pessoal depende do bem-estar dos demais. [...] No momento em que a sociedade puder recuperar para si mesma as condições de sua própria reprodução e puder instaurar uma lógica de relacionamento social baseada no respeito, incluindo o respeito à natureza, então a sociedade poderá recriar as condições de sua história e recuperá-la, no sentido de que a história é feita pelos seres humanos, e, consequentemente, eles podem transformá-la." Por Pablo Dávalos em: $<$ http://educacion.gob.ec/que-es-el-buen-vivir/> 
à cidadania participativa dos munícipes da região (por meio das Interações Culturais e Humanísticas) contribuindo para a aproximação entre escolas públicas e suas respectivas comunidades e, portanto, para a gestão democrática das escolas e municípios. (UFPR LITORAL, 2016, p. 10).

Estabelecer interfaces entre a ICH; a vivência; a auto-cartografia; a cartografia social; e a construção de geograficidades sobre o território do Litoral, torna esse espaço pedagógico, em um momento fundamental na formação do licenciado em geografia. Formação essa que entende o licenciado na perspectiva em que este é um educador em seu processo de alfabetização, de leitura do mundo, e está inserido em um projeto de sociedade que busque resistir ao discurso da exclusão. Assim, retomamos aqui a relevância das práticas extensionistas, bem como da Educação Popular na construção do curso. As temáticas do observatório, portanto, “(...) serão discutidas tendo como foco os princípios da educação popular: respeito às diferenças, solidariedade, senso crítico, propostas populares de transformação sócios espaciais, superação das formas de opressão, entre outros". (UFPR LITORAL, 2016, p. 12).

Ao ser construída a proposta curricular para a Licenciatura em Geografia estão implícitas, assim: apostas; desejos de que o espaço pedagógico da ICH potencialize os princípios de uma formação que não se feche em si mesma; que oportunize aos sujeitos ferramentas para compreender o mundo e assim agir sobre ele.

\section{Considerações}

Dentro do contexto das reflexões sobre o espaço pedagógico da $\mathrm{ICH}$, da proposta do curso de licenciatura em Geografia e da Educação Popular, a partir do vivido e dos desejos em movimento, entendemos que criar possibilidades diferenciadas no campo das práticas na universidade é um dos importantes desafios que se apresenta para a formação docente. Compreender a disputa pela legitimidade, entre o conhecimento hegemônico e os conhecimentos da/na materialidade dos sujeitos que constroem seus saberes, é uma opção política e epistemológica, afinal:

[...] fazer a Universidade desde a perspectiva da Educação Popular significa reconhecer que "não há justiça social global sem justiça cognitiva global, ou seja, sem justiça entre os conhecimentos" (SANTOS ${ }^{16}, 2007$, p.41). Assim,

\footnotetext{
${ }^{16}$ SANTOS, B. S. A Gramática do Tempo: para uma nova cultura política. São Paulo: Cortez, 2006. (Coleção: para um novo senso comum, v.4). 
importa considerar: quais as possibilidades de se efetivar um processo de aprendizagem coletiva e transformadora a partir da Universidade $\left(\right.$ SANTOS $\left.^{17}, 2006\right)$ ? (FREITAS e GHIGGI, 2013, p. 308).

Uma perspectiva extensionista e com práticas fundadas nos princípios da Educação Popular, portanto, traz para a pauta do debate questões que nos orientam na formação do licenciado. Em tempos onde os "Estados democráticos" na América Latina se veem ameaçados na esfera dos direitos humanos, dos direitos do trabalhador, dos direitos dos povos tradicionais e das mulheres, as ações de resistências são fundamentais no combate a projetos que ainda têm como argumento o mito da neutralidade ideológica na Educação, para que não encontrem, portanto, terreno fértil na escola para desenvolver seu projeto de sociedade.

\title{
THE PEDAGOGICAL SPACE OF CULTURAL AND HUMANISTIC INTERACTIONS AS A POTENTIALLY EXTENSIONIST SPACE IN TEACHER TRAINING COURSES
}

\begin{abstract}
:
With this work we have as main objective to present the pedagogical space called "cultural interactions and Humanities" (ICH) - contained in the political-pedagogical project (PPP) of Universidade Federal do Paraná (UFPR Litoral) - as a potential Space Extensionist in graduate courses. For both, our gaze is directed specifically to the course of Degree in geography of the UFPR Coast and the dialogs that this course proposes to establish with the ICH. The choice for this degree is due not only to be the most recent course of the UFPR coastline, but especially by the differentialit's Curricular Pedagogical Project (PPS). However, in addition to dealing with the course of degree in Geography, we will also introduce two experiences that characterize the ICH as a space potentially extensionist. The Humanistic and cultural interactions have as objective to promote the interaction between vertical (students of classes in different stages of courses) and horizontal (students from different courses in the same space). This is a pedagogical space that, based on the principles of popular education, has as its focus the collective construction and self-management processes, in order to provide insights and exchange of knowledge and experiences, which makes it a space for reflection and action. Thus, the pedagogical space is characterized as fundamental for the training courses for teachers, because it can provide ways of understanding and experiences about the spatiality and the territory, to the extent that it constitutes as articulator of dialogs the graduate courses and the local ways of life.
\end{abstract}

Keywords: Popular Education. University Extension. Training of Teachers. Humanistic and cultural interactions.

\section{REFERÊNCIAS}

\footnotetext{
${ }^{17}$ _. Renovar a Teoria Crítica e Reinventar a Emancipação Social. Tradução Mouzar Benedito. São Paulo: Boitempo, 2007. 
CARRILlo, A. T. A Educação Popular como Prática Política e Pedagógica Emancipadora. In STRECK, D.R.; ESTEBAN, M. T. (Orgs.). Educação popular: lugar de construção social coletiva. Petrópolis/RJ: Vozes, 2013.

CASTRO-GÓMEZ, S. Decolonizar launiversidad. La hybrisdelpunto cero y el diálogo de saberes. In: SAAVEDRA, J.L. (Ed.) Educación superior. interculturalidad y descolonización. La Paz: Pieb-Ceub, 2007.

DIEGUES, A. C. Enciclopédia Caiçara, vol. I, O Olhar do Pesquisador. São Paulo: Editora HUCITEC-NUPAUB-CEC/USP, 2004.

FONSÊCA, A. M.; MEDEIROS, M.O., Currículo em Alternância: uma nova perspectiva para a educação do campo. In QUEIROZ, J. B. P. (Orgs.) Pedagogia da Alternância construindo a educação do campo. Goiânia : Ed. da UCG; Brasília, Ed. Universa, 2006.

FREIRE, P. Extensão ou comunicação? $7^{\mathrm{a}}$ ed. Rio de Janeiro: Paz e Terra, 1983.

FREITAS, A. L. S.; GHIGGI, G. Da Delinquência e do Desperdício da Experiência ao Compromisso da Vida: dialogando convergências entre Educaçã Popular e o mundoda Universidade. In STRECK, D.R.; ESTEBAN, M. T. (Orgs.). Educação popular: lugar de construção social coletiva. Petrópolis/RJ: Vozes, 2013.

MASO, T. F. ; YATIM, L. . A (de)colonialidade do saber: uma análise a partir da Universidade Federal da Integração Latino-Americana (Unila). Paidéia (Belo Horizonte), v. XI, p. 31-53, 2014.

MENESES, M. P. Diálogos de Saberes, Debates de Poderes: possibilidades metodológicas para ampliar diálogos no Sul global. Em Aberto, 27, 91, 90-110. 2014.

PETERS, A. P., SCHONNR, G. M., TAUSCHECK, N.M. Descolonização de saberes e interculturalidade: a cultura cabocla, o conflito do contestado e seus ecos nos dias atuais. In CARVALHO, A. D (Org.) Interculturalidade, educação e encontro de pessoas e povos. Edições Afrontamento : Porto, 2013.

SAMPAIO, J.; SANTOS, G. C.; AGOSTINI, M. e SALVADOR, A. S. Limites e potencialidades das rodas de conversa no cuidado em saúde: uma experiência com jovens no sertão pernambucano. Interface (Botucatu) [online]. 2014, vol.18, suppl.2, p.1299-1311. Disponível em: <http://www.scielo.br/scielo.php?script=sci_arttext\&pid=S141432832014000601299\&lng=en\&nrm=iso>. Acessado em: 05/05/2018.

UFPR LITORAL. Projeto Pedagógico do curso de Licenciatura em Geografia. Matinhos. 2016.Disponível em: <http://www.litoral.ufpr.br/portal/wp-content/uploads/2016/10/PPCGeografia-Vers\%C3\%A3o-Final-AlteradoCoord-geral-estagio-of-11fev2016-1.pdf> . Acessado em: 20/06/2018.

UFPR LITORAL. Projeto Político Pedagógico. Matinhos. 2008.Disponível em: $<$ http://www.litoral.ufpr.br/portal/wp-content/uploads/2015/02/PPP-UFPR-LITORAL_Set2008_Alteracao_Dez-2008.pdf>. Acessado em: 20/06/2018. 